\title{
Identifying playing talent in professional football using artificial neural networks
}

Donald Barron ${ }^{1}$, Graham Ball ${ }^{2}$, Matthew Robins ${ }^{3}$, Caroline Sunderland ${ }^{4}$

1 School of Science, Technology and Engineering, University of Suffolk, Ipswich, UK (Email: d.barron2@uos.ac.uk, Tel: +44 (0)1473 338035).

2 John van Geest Cancer Research Centre, School of Science and Technology, Nottingham Trent University, Nottingham, UK (Email: graham.ball@,ntu.ac.uk, Tel: +44 (0)115 848 8308).

3 Institute of Sport, University of Chichester, Chichester, UK (Email: m.robins@chi.ac.uk, Tel: +44 (0)1243 816456).

4 Sport, Health and Performance Enhancement Research Centre, School of Science and Technology, Nottingham Trent University, Nottingham, UK (Email: caroline.sunderland@ntu.ac.uk,+44 (0)115 8486379).

Corresponding author: Donald Barron

Keywords: Soccer, Talent Identification, Premier League, Championship, Artificial Intelligence

\section{Acknowledgments}

The authors would like to thank STATS for providing access to the performance data that is used in this study. We would also like to thank Scout7 for providing access to their system to include biographical and international appearance data in the current study. 


\begin{abstract}
The aim of the current study was to identify key performance indicators in professional football that predict out-field players league status. The sample consisted of 966 players who completed the full 90 minutes during the 2008/09 or 2009/10 season in the Football League Championship. Players were assigned to one of three categories based on where they completed most of their match time in the following season, then split based on five positions including full backs $(n=205)$, centre backs $(n=193)$, centre midfielders $(n=205)$, wide midfielders $(n=168)$ and attackers $(n=195) .340$ performance, biographical and esteem variables were analysed using a Stepwise Artificial Neural Network approach. The models correctly predicted between $72.7 \%$ and $100 \%$ of test cases (Mean prediction of models $=$ $85.9 \%$ ), the test error ranged from $1.0 \%$ to $9.8 \%$ (Mean test error of models $=6.3 \%$ ). Variables related to passing, shooting, regains and international appearances were key factors in the predictive models. This is highly significant as objective position-specific predictors of league status have not previously been published. The method could be used to aid the identification and comparison of players as part of the due diligence process in professional football.
\end{abstract}




\section{Introduction}

Coaches and decision makers in professional football have traditionally used subjective observations to assess the performance of their team, to review the strengths and weaknesses of future opponents and to identify potential signings (Carling, Williams and Reilly, 2005). Match analysis research into the individual's performance in football has focused heavily on the physical demands of the sport (Carling, 2013). Research led by sport scientists with a heavy focus upon the physical aspects of performance in football has not managed to identify key predictors of match outcome or team success (Bradley et al., 2016; Carling, 2013).

However, studies investigating physical performance during matches have also incorporated technical elements and provided some insights into the successful performance of players and teams. Technical factors have been identified that are prominent predictors of team success and match outcome. Shots, shots on target and ball possession are the most commonly reported predictors (Castellano, Casamachina and Lago, 2012; Lagos-Penas, LagoBallesteros, Dellal and Gomez, 2010; Liu, Gomez, Lago-Penas and Sampaio, 2015). There has been a heavy emphasis on the attacking aspects of play linked to success and more detailed analysis is required into the defensive aspects of play to gain a greater understanding of the game.

Following on from the research into team success and physical profiles, there has been an increasing interest in the technical profiles of players. Studies have found positional differences in Ligue 1 in France, the Premier League in England and in Spain's La Liga (Dellal, Wong, Moalla and Chamari 2010; Dellal et al., 2011). The development of advanced computer systems has supported a greater understanding of position profiles in football. However, most of the research to date has used subjective methods to select variables for 
analysis (Taylor, Mellalieu and James, 2004) or they have replicated indicators used in other studies (Andrzejewski, Konefal, Chmura, Kowalczuk and Chmura, 2016). Using subjective criteria selection rather than exploring a broad spectrum of the data points has meant that many variables have yet to be assessed. Therefore, the impact of these variables upon playing success and career progression is unknown.

A broader analysis of player performance and career progression has been provided by using artificial neural networks to assess a wide range of variables (Barron, Ball, Robins and Sunderland, 2018). Artificial neural networks have been shown to be better at identifying patterns in complex non-linear data sets than forms of regression analysis and they are capable of generalizing results to solve real world problems (Basheer and Hajmeer, 2000; Lancashire, Lemetre and Ball, 2009; Tu, 1996). In a football context, artificial neural networks have been shown to be capable of creating models that can differentiate between specific groups and identify key variables that predict career progression (Barron et al, 2018). Previous studies though have been limited by assessing players regardless of position and their accuracy could be improved by making assessments of each position and the creation of position-specific career progression models.

To the authors' knowledge there has not been an objective study carried out to develop a position-specific predictive model that could support the scouting and recruitment process in professional football. The efficient and effective identification and assessment of transfer targets is a key aspect of any professional football club and requires a thorough due diligence process. Therefore, the aim of the current study was to develop an objective model to identify position-specific key performance indicators in professional football that predict out-field players league status using an artificial neural network. 


\section{Methods}

\section{Players and Match Data}

The basis of the current study followed Barron et al's (2018) method but looked to build on it and focus on position-specific assessments of players. The sample consisted of 966 out-field players (mean \pm SD age and height: $25 \pm 4 \mathrm{yr}, 1.81 \pm 0.06 \mathrm{~m}$ ) who had completed a full 90 minutes in the English Football League Championship during the 2008/09 and 2009/10 seasons (Table 1). Technical performance data and biographical data was collected using ProZone's MatchViewer software (ProZone Sports Ltd., Leeds, UK), the official Football League website (www.efl.com) and Scout7 Ltd's (Birmingham, UK) site. The Prozone MatchViewer system was used to collect performance data due to its accurate inter-observer agreement for the number and type of events (Bradley, O'Donoghue, Wooster and Tordoff, 2007). The data collected from the Prozone MatchViewer software was made available by STATS LLC (Chicago, USA). Institutional ethical approval was attained from the Non-Invasive Human Ethics Committee at Nottingham Trent University.

In total, 536 variables were collected in total including the total number, accuracy (\% success), means, medians and upper and lower quartiles of passes, tackles, possessions regained, clearances and shots. Additional data on total appearances, playing percentage, total goals and assists, international appearances and heights was also collected. The data set originally included 536 variables but low variance statistics were removed. After removing low variance data points, the data set included 340 variables for comparison. Each player's data was converted into mean performance data before they were assigned to one of three categories. 


\section{Player Grouping}

Players were allocated to one of five positions (full back, centre back, wide midfielder, central midfielder or attacker) based on where they spent most of their playing time during the season (See Table 1). They were then assigned to one of three categories based on where they went on to complete most of their match time during the following season. The first category included the players who completed most of their match time in a lower league during the following season. The second group included those players who completed most their match time in the English Football League Championship during the following season and the final category contained the players who progressed to complete most their match time in the English Premier League during the following season.

Sample sizes for each comparison were balanced to have an equal number of cases using a random number selector (i.e. 24 full backs were selected from group 0 to have an equal number of cases for comparisons to group 2). Players who played on loan during the $2008 / 09$ and 2009/10 seasons were included in the study but players who moved to a club outside England were excluded due to the complications in assessing the merits of foreign competitions against those in England. The five positions for each category of playing status were subsequently analysed using a Stepwise Artificial Neural Network approach to identify the optimal collection of variables for predicting playing status.

\section{Artificial Neural Network Model}

The artificial neural network modelling was based on the approach previously used successfully in gene profiling with breast cancer data (Lancashire et al., 2009) and used in 
assessing player performances in the Football League Championship (Barron et al., 2018). Further information on the artificial neural network model can be viewed in the supplementary information.

\section{Results}

Analysis using the artificial neural network created fifteen position-specific models to predict out-field player's league status. The models correctly predicted between $72.7 \%$ and $100 \%$ of test cases (Mean prediction of models $=85.9 \%$ ), the test error ranged from $1.0 \%$ to $9.8 \%$ (Mean test error of models $=6.3 \%$ ). Fourteen models correctly predicted $75 \%$ or more of the test players league status with an error of $9.6 \%$ or less (Table 2). The fifteen models, created in total, contained between five and twenty variables to predict the players league status with 134 variables in total being required to make the position models. The most prominent set of variables were those related to the players passing ability, with 48 of the 134 variables (35.8\%) being passing statistics. The next most prominent type of variable was related to players shooting. In total, twenty variables (14.9\%) related to shooting were selected in the models. Statistics related to regaining possession accounted for eleven of the variables $(8.2 \%)$ selected. Variables related to international appearances were selected nine times $(6.7 \%)$. A full outline of the categories of variables selected can be viewed in full (Table 3).

\section{Full Back Models}

The performance of the full back models as a group were the lowest of the five positions (Average test performance $=78.4 \% \pm 8.0 \%$ and average test error $=8.6 \% \pm 1.7 \%)($ Table 4$)$ The group $0 \mathrm{v} 1$ comparison had the lowest average test performance and highest test error out of all the models created (Average test performance $=72.7 \%$ and average test error $=9.8 \%$ ). Total appearances and mean percentage of backwards passes successful were key variables in 
the model (Table 5). The group $1 \vee 2$ comparison had an average test performance of $75 \%$ and a test error of $9.3 \%$. The percentage of sideways passes successful (upper quartile) and median total shots were the most prominent variables in the model (Table 6). The best full back model was for group $0 \mathrm{v} 2$ which had an average test performance of $87.5 \%$ and a test error of $6.6 \%$. The mean goals scored and minimum headers were the two most prominent factors in the model (Table 7).

\section{Centre Back Models}

The performance of the centre back models as a group had an average test performance of $94.4 \% \pm 5.1 \%$ and an average test error of $3.5 \% \pm 2.3 \%$. The group $0 \mathrm{v} 1$ model had an average test performance of $93.3 \%$ and an average test error of $4.1 \%$ using twenty variables. The percentage of successful passes in the opposition half (upper quartile) and shooting accuracy (upper quartile) were the most prominent variables in the model (Table 8). The group $1 \mathrm{v} 2$ model had the lowest average test performance and highest test error of the three centre back models (average test performance $=90.0 \%$ and average test error $=5.5 \%$ ). Backwards passes (lower quartile) and maximum short passes were the top two factors in the model (Table 9). The group $0 \mathrm{v} 2$ model had the highest average test performance of any model and the lowest test error of any model (average test performance $=100 \%$ and test error $=1.0 \%$ ). The group $0 \mathrm{v} 2$ centre back model contained eighteen variables with $0-6$ assists mean (group $0=0.1 \pm 0.1$, group $2=0.2 \pm 0.1$ ), mean shots on target inside the box (group 0 $=0.2 \pm 0.2$, group $2=0.3 \pm 0.2$ ) and minimum penalty area entries (Group $0=0.2 \pm 0.4$, Group $2=0 \pm 0$ ) being key variables (Table 10).

\section{Wide Midfielder Models}


The wide midfield models group average test performance was $84.8 \% \pm 13.2 \%$ with an average test error of $6.3 \% \pm 2.5 \%$. The group $0 \mathrm{v} 1$ model had an average test performance of $79.4 \%$ and a test error of $8.2 \%$. The maximum percentage of unsuccessful headers and forward passes successful (upper quartile) were the biggest predictors in the model (Table 11). The group $1 \mathrm{v} 2$ model had an average test performance of $77.8 \%$ and a test error of 7.4\%. U21 international caps and median forward passes unsuccessful were the most prominent factors in the model (Table 12). The group 0 v 2 model had the second highest average test performance and third lowest test error of all the models created (average test performance $=100 \%$ and a test error of $3.4 \%$ ). The group $0 \mathrm{v} 2$ wide midfielder model contained six variables including: total goals (group $0=1.4 \pm 1.9$, group $2=5.5 \pm 3.8$ ), passes attempted opposition half upper quartile (group $0=16.2 \pm 6.3$, group $2=21.4 \pm 5.8$ ), fouls in the defensive third mean (group $0=0.2 \pm 0.2$, group $2=0.3 \pm 0.3$ ), total shots on target (excluding blocked) maximum (group $0=1.0 \pm 0.8$, group $2=2.6 \pm 1.1$ ), $\%$ forward passes successful mean (group $0=53.4 \% \pm 14.8 \%$, group $2=55.2 \% \pm 9.7 \%$ ) and forward passes successful median (group $0=5.0 \pm 3.2$, group $2=6.1 \pm 2.2$ ) (Table 13).

\section{Centre Midfielder Models}

The best overall average was for the centre midfielder's models as a group (Average test performance $=86.1 \% \pm 6.6$ and average test error $=6.8 \% \pm 2.5)$. The group $0 \mathrm{v} 1$ model had the lowest average test performance of the centre midfield models and had the second highest test error across all models (Average test performance $=78.6 \%$ and average test error $=$ 9.6\%). Fouls and maximum first time passes were the most prominent variables in the model (Table 14). The group $1 \mathrm{v} 2$ model had an average test performance of $88.9 \%$ and a test error of $5.9 \%$. Successful passes (lower quartile) and penalty area entries (lower quartile) were two key variables in the model (Table 15). The group $0 \mathrm{v} 2$ model had an average test 
performance of $90.9 \%$ and a test error of $4.8 \%$. The number of starts and maximum shots on target outside the box were the highest predictors in the model (Table 16).

\section{Attacker Models}

The performance of the attacker models as a group had an average test performance of $84.7 \%$ $\pm 6.6 \%$ and an average test error of $6.2 \% \pm 3.2 \%$. The group $0 \mathrm{v} 1$ model had an average test performance of $80 \%$ and an average test error of $8.7 \%$. The most prominent variables in the model were international caps and the number of touches (lower quartile) (Table 17). The group $1 \mathrm{v} 2$ model had an average test performance of $81.8 \%$ and a test error of $7.2 \%$. U21 international caps and international caps were the two most important factors in the model (Table 18). The best average test performance for an attacker model was recorded for the group $0 \mathrm{v} 2$ model and it had the lowest overall test error of all models (average test performance $=92.3 \%$ and test error $=2.6 \%$ ). The group $0 \mathrm{v} 2$ attacker model contained ten variables with total goals (group $0=2.7 \pm 3.0$, group $2=10.0 \pm 6.2$ ), blocks upper quartile (group $0=1.0 \pm 0.5$, group $2=1.5 \pm 0.7$ ) and short passes minimum (group $0=4.9 \pm 2.5$, group $2=4.3 \pm 2.4$ ) being key variables (Table 19).

\section{Model Comparisons}

The models produced comparing positions for group $0 \mathrm{v} 1$ had the lowest overall average test performance and highest test error (mean test performance $=80.8 \% \pm 7.6 \%$ and average test error $=8.1 \% \pm 2.3 \%$ ). The overall average test performance across all five positions for group $1 \mathrm{v} 2$ comparisons was $82.7 \% \pm 6.6 \%$ and the average test error was $7.1 \% \pm 1.5$. The highest overall average test performance across the five positions was for group $0 \mathrm{v} 2$ (mean test performance $=94.1 \% \pm 5.6 \%$ and average test error $=3.7 \% \pm 2.1 \%$ (Table 20$)$. The top three models produced by the neural network were for $0 \mathrm{v} 2$ centre back (average test performance $100 \%$ and $1.0 \%$ test error), group $0 \mathrm{v} 2$ wide midfielder (average test performance $100 \%$ and 
$3.4 \%$ test error) and group $0 \mathrm{v} 1$ centre back (average test performance $93.3 \%$ and $4.1 \%$ test error). The means and standard deviations for key variables for the top three models can be reviewed in full (Tables 21-23).

\section{Discussion}

The aim of the current study was to develop objective models that identified position-specific key performance indicators that predict out-field players league status. The artificial neural network created fifteen position-specific models to predict out-field players league status. The artificial neural network's ability to correctly classify more than $75 \%$ of the players league status for fourteen different position comparisons is a key result. This surpasses the previous prediction rates reported using artificial neural networks in other team sports, such as those undertaken in cricket (Iyer and Sharda, 2009; Saikia, Bhattacharjee and Lemmer, 2012). Their studies could predict classification of batsmen and bowlers with accuracy levels ranging from $49 \%$ to $77 \%$. In individual sports, artificial neural networks have been able to predict $80.2 \%$ of gymnast's future classifications based on a multi-dimensional testing process (Pion, Hohmann, Liu, Lenoir and Segers, 2017). Therefore, the current artificial neural network prediction rates are among the highest reported to date in an athlete classification study.

\section{Passing Variables}

The most prominent set of variables were those related to the players passing ability, with 48 of the 134 total variables included in models (35.8\%) being passing statistics. Many passing variables have been highlighted previously as key indicators when differentiating between players of various playing levels and linked to team success (Bradley et al., 2013; Rampinini, Impellizzerie, Castagna, Coutts and Wisloff, 2009). Comparisons between players within the 
English football pyramid showed that players in the Premier League performed a greater number of total passes, successful passes and forward passes (Bradley et al., 2013). Out of the 48 passing variables identified in the models, 29 were related to the success of the passing variables. The passing variables related to their success were a mixture of 27 different statistics accounting for the direction (forwards, sideways and backwards) of the pass, the origin of the pass (own half or opposition half) and the mean, median, minimum, maximum and upper and lower quartile figure for different variables.

In further agreement with Bradley and colleagues (2013) findings, thirteen of the passing variables were related to forward passing. Forward passes have been shown to have the lowest chance of success when compared to sideways or backwards passes (Szczepanski and McHale, 2016). Yet, to create scoring opportunities and in turn score goals players are required to progress the play with forward passing. Variables relating to forward passes appeared in models for full backs (group $0 \vee 1$ and group $0 \vee 2$ ), centre backs (group $0 \vee 1$ ), wide midfield (group $0 \mathrm{v} 1$, group $1 \mathrm{v} 2$ and group $0 \mathrm{v}$ 2), centre midfield (group $0 \mathrm{v} 1$ and group $0 \mathrm{v} 2$ ) but did not feature prominently in any models for attackers. This would appear logical as attackers play in more advanced areas and have fewer opportunities to perform forward passes. The prevalence of forward passing variables for a number of positions and different comparisons highlights its importance in playing success.

The current study also highlighted two variables related to short passing with the maximum and minimum variables being selected in two models (group $1 \mathrm{v} 2$ centre back and group $0 \mathrm{v}$ 2 attacker). Research into factors that distinguish between top four and bottom four English Premier League teams highlighted short passes as a key variable (Adams, Morgans, Sacramento, Morgan and Williams, 2013). Specifically, the mean frequency of successful 
short passes played by centre backs and full backs was the biggest factor differentiating between the two groups.

Using the artificial neural network methodology has highlighted some overlap between factors previously identified by research articles. The current study has also identified novel findings for variables that have not previously been analysed or identified as key variables. Eight passing variables were related to those in the opposition half and they appeared in six different position models (group $0 \mathrm{v} 1$ centre back, group $0 \mathrm{v} 1$ and $0 \mathrm{v} 2$ centre midfield, group $0 \mathrm{v} 1$ and $0 \mathrm{v} 2$ wide midfield and $0 \mathrm{v} 2$ attacker models). Six of the variables were also related to first time passes played and they appeared in the group $0 \mathrm{v} 1$ and $0 \mathrm{v} 2$ centre back, group 1 v 2 full back, group $0 \mathrm{v} 1$ and $1 \mathrm{v} 2$ centre midfield and group $0 \mathrm{v} 1$ attacker models. Passes in the opposition half indicate possession taking place in more offensive pitch locations and could indicate the involvement of players in attacking moves. The ability to pass the ball accurately over a range of distances and directions is a key factor in performance and for differentiating between players of varying ability. This is accepted knowledge amongst coaches but the models have accurately identified specific key variables and provided an objective assessment of their impact on league status.

\section{Shooting Variables}

The next most prominent type of variable was related to players shooting ability. In total, twenty variables $(14.9 \%)$ related to shooting were selected in the models. This agrees with previous research into team success in football, with total shots and shooting accuracy being the most commonly reported predictors in matches (Castellano et al., 2012; Lagos-Penas et al., 2010; Liu et al., 2015). Surprisingly, all positions except attacker included shooting variables in the models created in the current study. However, one of the attacker models (group $0 \vee 2$ ) did include total goals as a key variable. Many teams now prefer to play with 
one lone attacker in their line-up that spreads the need for scoring goals throughout the team and the requirements of the centre forward position could be changing as a result (Adams et al., 2013).

\section{Attacking Entries}

Other attacking variables selected as part of the models were related to crossing and entries into the final third and penalty area. Final third and penalty area entries were selected three times and in three different models. Crosses are a factor that have been repeatedly identified as being key to differentiating between successful and unsuccessful teams (Lagos-Penas et al., 2010; Lagos-Penas et al., 2011). They have not been identified as key when differentiating between players of different performance levels previously, they were only selected twice in the current study meaning they did not play a prominent role in the position models. The mean number of crosses were selected in the group $0 \mathrm{v} 2$ attacker model (crosses mean group $01.0 \pm 0.8$, group $21.75 \pm 1.23$ ). The inclusion of the number of crosses in the attacker model and the higher values reported for group 2 may offer more evidence for the evolving role of the attacker.

As well as crosses, final third and penalty area entries were selected three times and in three different models. Previous research has indicated that penalty area entries differentiate between winning and losing teams (Ruiz-Ruiz, Fradua, Fernandez-Garcia and Zubillaga, 2013). However, in the current study they were selected in one model for centre backs (group $0 \mathrm{v} 2$ ), the centre backs from players dropping down to a lower playing level reported higher values (minimum penalty area entries group $00.2 \pm 0.4$, group $20.0 \pm 0.0$ ). The identification of minimum penalty area entries in the centre back model and group 0 having a higher value is a novel finding. It may appear counter intuitive but centre backs who drop down to a lower 
level may play in teams who use a more direct style of play and play longer passes from their centre backs as opposed to building the play with shorter passing combinations.

\section{Defensive Variables}

The models also highlighted several defensive variables as key predictors of league status. Statistics related to regaining possession accounted for eleven of the variables $(8.2 \%)$. Previous research into match outcomes and players technical and tactical ability has heavily focused on the attacking aspects of play (Mackenzie and Cushion, 2013), passing (Adams et al., 2013; Szczepanski and McHale, 2016) and possession (Castellano et al., 2012; Collett, 2013; Lagos-Penas et al., 2010; Liu et al., 2015). A limited number of defensive variables have been researched or identified that are linked to success. A balanced defensive shape (Tenga, Holme, Ronglan and Bahr, 2010), defensive reaction after losing possession (Vogelbein, Nopp and Hokelmann, 2014) and regaining possession in the final third have been identified previously (Almeida, Ferreira and Volossovitch, 2014).

The current study highlighted possession won based on the minimum, median, maximum and upper quartile variables as being key predictors of league status. Possession gained upper quartile and interceptions median and maximum were also selected as key variables in models. The defensive variables were not selected as part of any of the full back models. They were commonly selected as part of the wide midfield (group $0 \mathrm{v} 1$ and group $1 \mathrm{v} 2$ ) and attacker models (group $1 \vee 2$ and group $0 \vee 2$ ). This may appear counter intuitive and these factors would not normally be assessed when profiling more attacking positions within the team. Modern playing philosophies valuing high pressing tactics from forward players to 
regain possession in more advanced areas of the pitch, this may explain the importance of these factors in wide midfield and attacker models within the current study (Perarnau, 2014).

\section{International Recognition}

Other key variables selected throughout several models relate to international appearances, international caps and U21 international caps were selected nine times $(6.7 \%)$ in total. This is a novel finding as previous assessments of player's performances have limited themselves to match performance and season totals of performance data. Previous research into international recognition and team or playing success has not been undertaken to the author's knowledge. However, international recognition has been found to be linked with player salary allocation, particularly at the higher levels of the game (Frick, 2011).

\section{Position-Specific Models}

The current study created a number of strong predictive models for player's league status, there were also some key findings relating to the prediction rates of specific positions. Three of the five positions had very similar levels of classification accuracy (centre midfield $86.1 \%$, wide midfield $85.7 \%$ and attacker $84.7 \%$ ) but the full back position's overall accuracy was only $78.4 \%$ and the centre back position's overall accuracy was $94.4 \%$. The full back results are still an important finding but below the levels reported for other positions. The group $0 \mathrm{v}$ 1 full back model had the lowest classification accuracy of all the models and the group $1 \mathrm{v} 2$ full back model had the second lowest classification accuracy. The full back position is one that requires a complex set of technical and tactical skills as it requires a wide array of attacking and defensive qualities (Bush, Archer, Hogg and Bradley, 2015). 
Recent evaluations of the changes within performance data for playing positions has shown extensive changes over time in the Premier League (Bush et al., 2015). Pronounced increases were found for the levels of high-speed running and the distances covered while sprinting, with full backs showing the largest increases between 2006-07 and 2012-13 (Bush et al., 2015). Therefore, the full back position may be influenced more by the physical aspects of performance. This could explain the lower prediction rates for full backs due to the lack of physical tracking data being available.

\section{Study Limitations}

Strong models were identified for fourteen out of the fifteen position comparisons assessed but there are some limitations to the present study that should be addressed in future research. The match running performance data for players was not available for the current study. There is an acceptance amongst the sports science community that running performance is not a predictor of team success or match outcome (Bradley et al., 2016; Carling, 2013). However, including match running performance data could provide a higher level of classification accuracy for some of the positions assessed. Another limitation of the study is the lack of contextual data available and the inability of the data to provide a detailed assessment for off the ball parameters. The final limitation of the study relates to the sample size for players progressing to play in the Premier League. The samples for the players progressing from the five positions to play in the Premier League were the smallest of all the groupings. Statistical power tests on similar sample sizes have reached the required levels (Lancashire et al., 2009). However, future studies should look to increase the sample available to increase confidence that the results are repeatable to new cases. 


\section{Conclusions}

The current study has shown that artificial neural networks are a valid and highly effective tool to classify and predict players league status. Fourteen models across all five positions were created that provided strong prediction accuracy levels for players league status. This is an important result as it outlines an objective methodology that can aid the scouting and recruitment process in professional football. The process of identifying and recruiting players in professional football has largely been a subjective process in the past. Further research should look to combine assessments of physical and technical performance data to provide a more accurate prediction of league status. Studies should also look to create models to predict the career progression of players from multiple leagues to provide a better practical tool for scouting and recruitment purposes. The combination of subjective assessments and more objective tools could lead to a more effective overall process in the highly competitive football transfer market.

\section{$\underline{\text { References }}$}

Adams, D., Morgans, R., Sacramento, J., Morgan, S., and Williams, M. D., 2013. Successful short passing frequency of defenders differentiates between top and bottom four English Premier League teams. International Journal of Performance Analysis in Sport, 13, pp. 653668.

Almeida, C. H., Ferreira, A. P., and Volossovitch, A., 2014. Effects of match location, match status and quality of opposition on regaining possession in UEFA Champions League. Journal of Human Kinetics, 41 (2014), pp. 2013-214.

Andrzejewski, M., Konefal, M., Chmura, P., Kowalczuk, E., and Chmura, J., 2016. Match outcome and distances covered at various speeds in match play by elite German soccer players. International Journal of Performance Analysis in Sport, 16 (3), pp. 817-828. 
Basheer, I.A., and Hajmeer, M., 2000. Artificial neural networks: fundamentals, computing, design and application. Journal of Microbiological Methods, 43 (2000), pp. 3-31.

Bradley, P. S., Archer, D., Hogg, B., Schuth, G., Bush, M., Carling, C., and Barnes, C., 2016. Tier-specific evolution of match performance characteristics in the English Premier League: It's getting tougher at the top. Journal of Sports Sciences, 34 (10), pp. 980-987.

Bradley, P. S., Carling, C., Diaz, A. G., Hood, P., Barnes, C., Ade, J., Boddy, M., Krustrup, P., and Mohr, M., 2013. Match performance and physical capacity of players in the top three competitive standards of English professional soccer. Human Movement Science, 32 (2013), pp. 808-821.

Bradley, P. S., O’Donaghue, P., Wooster, B., and Tordoff, P., 2007. The reliability of ProZone MatchViewer: a video-based technical performance analysis system. International Journal of Performance Analysis in Sport, 7 (3), pp. 117-129.

Bush, M. D., Archer, D. T., Hogg, R., and Bradley, P. S., 2015. Factors influencing physical and technical variability in the English Premier League. International Journal of Sports Physiology and Performance, 10, pp. 865-872.

Carling, C., 2013. Interpreting physical performance in professional soccer match-play: Should we be more pragmatic in our approach. Sports Medicine, 43 (2013), pp. 655-663.

Carling, C., Williams, A. M., and Reilly, T. R., 2005. Handbook of soccer match analysis: A systematic approach to improving performance. London: Routledge.

Castellano, J., Casamichana, D., and Lago, C., 2012. The use of match statistics that discriminate between successful and unsuccessful soccer teams. Journal of Human Kinetics, 31 (2012), pp. 139-147.

Collett, C., 2013. The possession game? A comparative analysis of ball retention and team success in European and international football, 2007-2010. Journal of Sports Sciences, 31 (2), pp. 123-136. 
Dellal, A., Chamari, K., Wong, D. P., Ahmaidi, S., Keller, D., Barros, R., Bisciotti, G. N., and Carling, C., 2011. Comparison of physical and technical performance in European soccer match-play: FA Premier League and La Liga. European Journal of Sport Science, 11 (1), pp. $51-59$.

Dellal, A., Wong, D. P., Moalla, W., and Chamari, K., 2010. Physical and technical activity of soccer players in the French First League - with special reference to their playing position. International SportMed Journal, 11 (2), pp. 278-290.

Frick, B., 2011. Performance, salaries, and contract length: Empirical evidence from German soccer. International Journal of Sport Finance, 6, pp. 87-118.

Iyer, S., R., and Sharda, R., 2009. Prediction of athletes performance using neural networks: An application in cricket team selection. Expert systems with applications, 36 (2009), pp. $5510-5522$.

Lancashire, L. J., Lemetre, C., and Ball, G. R., 2009. An introduction to artificial neural networks in bioinformatics - application to complex microarray and mass spectrometry datasets in cancer studies. Briefings in Bioinformatics, 10 (3), pp. 315-329.

Lago-Penas, C., Lago-Ballesteros, J., Dellal, A., and Gomez, M., 2010. Game-related statistics that discriminated winning, drawing and losing teams from the Spanish soccer league. Journal of Sports Science and Medicine, 9, pp. 288-293.

Liu, H., Gomez, M. A., Lago-Penas, C., and Sampaio, J., 2015. Match statistics related to winning in the group stage of 2014 Brazil FIFA World Cup. Journal of Sports Sciences, 33 (12), pp. 1205-1213.

Mackenzie, R., and Cushion, C., 2013. Performance analysis in football: A critical review and implications for future research. Journal of Sports Sciences, 31 (6), pp. 639-676.

Perarnau, M., 2014. Pep confidential: The inside story of Pep Guardiola's first season at Bayern Munich. Edinburgh: Arena Sport. 
Pion, J., Hohmann, A., Liu, T., Lenoir, M., \& Segers, V. (2017). Predictive models reduce talent development costs in female gymnastics. Journal of Sports Sciences, 35(8), 806-811.

Rampinini, E., Impellizzeri, F. M., Castagna, C., Coutts, A. J., and Wisloff, U., 2009. Technical performance during soccer matches of the Italian Serie A league: Effect of fatigue and competitive level. Journal of Science and Medicine in Sport, 12, pp. 227-233.

Ruiz-Ruiz, C., Fradua, L., Fernandez-Garcia, A., and Zubillaga, A., 2013. Analysis of entries into the penalty area as a performance indicator in soccer. European Journal of Sport Science, 13 (3), pp. 241-248.

Saikia, H., Bhattacharjee, D., and Lemmer, H., H., 2012. Predicting the performance of bowlers in IPL: An application of artificial neural network. International Journal of Performance Analysis in Sport, 12 (1), pp. 75-89.

Salkind, N., J., 2010. Encyclopedia of research design. California: Sage.

Taylor, J., B., Mellalieu, S., and James, N., 2004. Behavioural comparisons of positional demands in professional soccer. International Journal of Performance Analysis in Sport, 4 (1), pp. 81-97.

Tenga, A., Holme, I., Ronglan, L. T., and Bahr, R., 2010. Effects of playing tactics on goal scoring in Norwegian professional soccer. Journal of Sports Sciences, 28 (3), pp. 237-244.

Tu, J. V., 1996. Advantages and disadvantages of using artificial neural networks versus logistic regression for predicting medical outcomes. Journal of Clinical Epidemiology, 49 (11), pp. 1225-1231.

Vogelbein, M., Nopp, S., and Hokelmann, A., 2014. Defensive transition in soccer - are prompt possession regains a measure of success? A quantitative analysis of German FusballBundesliga 2010/11. Journal of Sports Sciences, 32 (11), pp. 1076-1083. 

Table 1. Biographical data represented as means and standard deviations for player groupings.

\begin{tabular}{llllll}
\hline Group & Players (n) & Age (years) & Height (cm) & 90 Minute Appearances & Total Minutes \\
\hline Group 0 Full Back & 56 & $24.2 \pm 4.3$ & $180.5 \pm 4.4$ & $10.1 \pm 10.7$ & $1112 \pm 1040$ \\
Group 1 Full Back & 125 & $24.9 \pm 4.2$ & $180.2 \pm 4.3$ & $20.0 \pm 12.1$ & $2603 \pm 1107$ \\
Group 2 Full Back & 24 & $25.4 \pm 3.3$ & $179.7 \pm 3.6$ & $18.5 \pm 12.5$ & $1919 \pm 1200$ \\
Group 0 Centre Back & 37 & $27.5 \pm 5.1$ & $187.2 \pm 5.1$ & $15.9 \pm 10.9$ & $15901 \pm 1023$ \\
Group 1 Centre Back & 131 & $25.6 \pm 3.7$ & $186.7 \pm 4.2$ & $22.5 \pm 12.4$ & $2186 \pm 1116$ \\
Group 2 Centre Back & 25 & $25.6 \pm 3.4$ & $187.4 \pm 3.7$ & $22.8 \pm 12.0$ & $2173 \pm 1141$ \\
Group 0 Wide Midfield & 42 & $24.4 \pm 4.3$ & $179.1 \pm 5.5$ & $6.6 \pm 7.0$ & $1119 \pm 858$ \\
Group 1 Wide Midfield & 103 & $24.6 \pm 3.7$ & $177.2 \pm 5.6$ & $12.6 \pm 9.6$ & $1840 \pm 1000$ \\
Group 2 Wide Midfield & 23 & $24.8 \pm 3.7$ & $179.2 \pm 4.8$ & $19.4 \pm 11.5$ & $2425 \pm 1109$ \\
Group 0 Centre Midfield & 36 & $25.6 \pm 4.8$ & $179.7 \pm 5.1$ & $12.4 \pm 11.9$ & $1505 \pm 1147$ \\
Group 1 Centre Midfield & 148 & $25.6 \pm 3.9$ & $178.8 \pm 5.8$ & $19.5 \pm 11.1$ & $2238 \pm 1006$ \\
Group 2 Centre Midfield & 21 & $26.3 \pm 4.5$ & $178.5 \pm 4.5$ & $25.6 \pm 13.6$ & $2693 \pm 1253$ \\
Group 0 Attacker & 38 & $26.6 \pm 4.8$ & $182.2 \pm 6.5$ & $6.2 \pm 6.9$ & $1096 \pm 920$ \\
Group 1 Attacker & 130 & $26.0 \pm 3.9$ & $181.6 \pm 5.9$ & $11.8 \pm 9.3$ & $1845 \pm 931$ \\
Group 2 Attacker & 27 & $26.2 \pm 4.5$ & $181.7 \pm 5.8$ & $13.2 \pm 9.3$ & $2081 \pm 930$ \\
\hline
\end{tabular}


Table 2. Results for all models with balanced data sets. The best average test performance $=$ $100.0 \%$ and the best average test error $=1.0 \%$ (Using a combination of eighteen variables) Centre Back Group 0 v 2. The worst average test performance $=72.7 \%$ and the worst average test error $=9.8 \%$ (Using a combination of five variables) - Full Back Group $0 \mathrm{v} 1$.

\begin{tabular}{|c|c|c|c|c|}
\hline Position & Groups & Average Test Performance (\%) & Average Test Error (\%) & $\begin{array}{l}\text { Number of } \\
\text { Variables }\end{array}$ \\
\hline Full Back & $0 \mathrm{v} 1$ & 72.7 & 9.8 & 5 \\
\hline Full Back & $0 \vee 2$ & 87.5 & 6.5 & 10 \\
\hline Full Back & $1 \vee 2$ & 75 & 9.3 & 6 \\
\hline Centre Back & $0 \mathrm{v} 1$ & 93.3 & 4.1 & 20 \\
\hline Centre Back & $0 \mathrm{v} 2$ & 100 & 1.0 & 18 \\
\hline Centre Back & $1 \vee 2$ & 90 & 5.5 & 6 \\
\hline Wide Midfield & $0 \mathrm{v} 1$ & 76.5 & 8 & 10 \\
\hline Wide Midfield & $0 \vee 2$ & 100 & 3.4 & 6 \\
\hline Wide Midfield & $1 \mathrm{v} 2$ & 77.8 & 7.4 & 9 \\
\hline Centre Midfield & $0 \mathrm{v} 1$ & 78.6 & 9.6 & 9 \\
\hline Centre Midfield & $0 \vee 2$ & 90.9 & 4.8 & 10 \\
\hline Centre Midfield & $1 \vee 2$ & 88.9 & 5.9 & 5 \\
\hline Attacker & $0 \mathrm{v} 1$ & 80 & 8.7 & 5 \\
\hline Attacker & $0 \mathrm{v} 2$ & 92.3 & 2.6 & 10 \\
\hline Attacker & $1 \mathrm{v} 2$ & 81.8 & 7.2 & 6 \\
\hline Average & NA & 85.7 & 6.3 & 9.0 \\
\hline
\end{tabular}


Table 3. Summary of the variables in all position models by grouping.

\begin{tabular}{|c|c|c|}
\hline Variable Grouping & Times Selected & Selected $(\%)$ \\
\hline Passing & 48 & 35.8 \\
\hline Shooting & 20 & 14.9 \\
\hline Regains & 11 & 8.2 \\
\hline International Appearances & 9 & 6.7 \\
\hline Heading & 8 & 6.0 \\
\hline Fouls & 5 & 3.7 \\
\hline Goals & 5 & 3.7 \\
\hline Appearances & 4 & 3.0 \\
\hline Entries & 3 & 2.2 \\
\hline Possession Lost & 4 & 3.0 \\
\hline Tackled & 3 & 2.2 \\
\hline Time in Possession & 3 & 2.2 \\
\hline Assists & 2 & 1.5 \\
\hline Blocks & 2 & 1.5 \\
\hline Clearances & 2 & 1.5 \\
\hline Crossing & 2 & 1.5 \\
\hline Touches & 2 & 1.5 \\
\hline Balls Received & 1 & 0.7 \\
\hline Possessions & 1 & 0.7 \\
\hline
\end{tabular}


Table 4. Comparison of overall average test performance scores from position models as means and standard deviations.

\begin{tabular}{lll}
\hline Position Comparison & Overall Average Test Performance (\%) & Overall Average Test Error (\%) \\
\hline Full Back & $78.4 \pm 8.0$ & $8.6 \pm 1.7$ \\
Centre Back & $94.5 \pm 5.1$ & $3.5 \pm 2.3$ \\
Wide Midfield & $84.8 \pm 13.2$ & $6.3 \pm 2.5$ \\
Centre Midfield & $86.1 \pm 6.6$ & $6.8 \pm 2.5$ \\
Attacker & $84.7 \pm 6.6$ & $6.2 \pm 3.2$ \\
\hline
\end{tabular}

Table 5. Results for Group $0 \mathrm{v}$ Group 1 Full Back balanced data set comparison. The best average test performance $=72.7 \%$ and the best average test error $=9.8 \%$ (Using a combination of five variables).

\begin{tabular}{llll}
\hline Rank & Variable & Average Test Performance (\%) & Average Test Error (\%) \\
\hline 1 & Total Appearances & 63.6 & 11.2 \\
2 & \% Backwards Passes Successful (Mean) & 72.7 & 10.6 \\
3 & Total Minutes & 72.7 & 9.8 \\
4 & \% Forwards Passes Successful (Mean) & 72.7 & 9.8 \\
5 & Forwards Passes (Maximum) & 72.7 & 9.8 \\
6 & Blocks (Mean) & 70.5 & 9.9 \\
7 & \% Unsuccessful Headers (Median) & 68.2 & 10.0 \\
8 & Forward Passes Successful (Median) & 68.2 & 10.0 \\
9 & \% Passes Successful Own Half (Mean) & 72.7 & 9.9 \\
10 & Passes Own Half 25\% (Lower Quartile) & 72.7 & 10.0 \\
\hline
\end{tabular}


Table 6. Results for Group $1 \mathrm{v}$ Group 2 Full Back balanced data set comparison. The best average test performance $=75.0 \%$ and the best average test error $=9.3 \%$ (Using a combination of six variables).

\begin{tabular}{llll}
\hline Rank & Variable & $\begin{array}{l}\text { Average Test } \\
\text { Performance (\%) }\end{array}$ & $\begin{array}{l}\text { Average Test Error } \\
(\%)\end{array}$ \\
\hline 1 & \% Sideways Passes Successful 75\% (Upper Quartile) & 60.0 & 11.3 \\
2 & Total Shots (Median) & 60.0 & 10.9 \\
3 & International Caps & 70.0 & 9.7 \\
4 & Tackled (Mean) & 70.0 & 9.3 \\
5 & First Time Passes (Maximum) & 70.0 & 9.1 \\
6 & Number of Possessions (Median) & 75.0 & 9.3 \\
7 & Tackled (Minimum) & 70.0 & 9.4 \\
8 & \% Sideways Passes Successful 25\% (Lower Quartile) & 70.0 & 9.4 \\
9 & Total Assists & 70.0 & 9.8 \\
10 & \% First Time Passes Unsuccessful 25\% (Lower Quartile) & 70.0 & 9.8 \\
\hline
\end{tabular}

Table 7. Results for Group $0 \mathrm{v}$ Group 2 Full Back balanced data set comparison. The best average test performance $=87.5 \%$ and the best average test error $=6.6 \%$ (Using a combination of ten variables).

\begin{tabular}{llll}
\hline Rank & Variable & $\begin{array}{l}\text { Average Test } \\
\text { Performance (\%) }\end{array}$ & $\begin{array}{l}\text { Average Test Error } \\
(\%)\end{array}$ \\
\hline 1 & Goals (Mean) & 75.0 & 9.1 \\
2 & Headers (Minimum) & 75.0 & 8.6 \\
3 & \% Forward Passes Unsuccessful (Mean) & 81.3 & 8.2 \\
4 & Shots Off Target (Exc. Blocked) (Maximum) & 78.1 & 8.1 \\
5 & \% Forward Passes Unsuccessful 75\% (Upper Quartile) & 75.0 & 8.2 \\
6 & U21 Caps & 75.0 & 8.0 \\
7 & Shots Inside the Box (Mean) & 81.3 & 7.7 \\
8 & Possession Lost (Mean) & 81.3 & 7.0 \\
9 & Shots On Tgt Outside the Box (Maximum) & 81.3 & 7.2 \\
10 & Total Assists & 87.5 & 6.6 \\
\hline
\end{tabular}


Table 8. Results for Group $0 \mathrm{v}$ Group 1 Centre Back balanced data set comparison. The best average test performance $=93.3 \%$ and the best average test error $=4.1 \%$ (Using a combination of twenty variables).

\begin{tabular}{|c|c|c|c|}
\hline Rank & Variable & $\begin{array}{l}\text { Average Test } \\
\text { Performance (\%) }\end{array}$ & $\begin{array}{l}\text { Average Test Error } \\
(\%)\end{array}$ \\
\hline 1 & \% Passes Successful Opp Half 75\% (Upper Quartile) & 66.7 & 10.9 \\
\hline 2 & Shooting Accuracy 75\% (Upper Quartile) & 73.3 & 9.3 \\
\hline 3 & \% Successful Headers 75\% (Upper Quartile) & 80.0 & 7.6 \\
\hline 4 & Balls Received 75\% (Upper Quartile) & 80.0 & 7.6 \\
\hline 5 & Crosses (Median) & 80.0 & 7.9 \\
\hline 6 & \% First Time Passes Successful 25\% (Lower Quartile) & 80.0 & 6.8 \\
\hline 7 & Total Shots on Target (Mean) & 86.7 & 6.4 \\
\hline 8 & Passes Successful Opp Half (Minimum) & 86.7 & 6.0 \\
\hline 9 & U21 Caps & 86.7 & 6.1 \\
\hline 10 & Shooting Accuracy 25\% (Lower Quartile) & 86.7 & 5.2 \\
\hline 11 & Medium Passes (Mean) & 86.7 & 5.2 \\
\hline 12 & Forward Passes Successful (Minimum) & 93.3 & 4.5 \\
\hline 13 & Total Shots on Tgt (Excluding Blocked) (Mean) & 86.7 & 5.0 \\
\hline 14 & Goals (Mean) & 86.7 & 4.5 \\
\hline 15 & \% Unsuccessful Headers 25\% (Lower Quartile) & 90.0 & 4.7 \\
\hline 16 & Long Passes (Median) & 93.3 & 4.5 \\
\hline 17 & \% Passes Successful Opp Half (Minimum) & 93.3 & 4.2 \\
\hline 18 & Avg Time in Possession (Mean) & 86.7 & 4.8 \\
\hline 19 & \% Forwards Passes Successful (Minimum) & 86.7 & 4.7 \\
\hline 20 & Shooting Accuracy (Median) & 93.3 & 4.1 \\
\hline
\end{tabular}


Table 9. Results for Group $1 \mathrm{v}$ Group 2 Centre Back balanced data set comparison. The best average test performance $=90.0 \%$ and the best average test error $=5.5 \%$ (Using a combination of six variables).

\begin{tabular}{llll}
\hline Rank & Variable & $\begin{array}{l}\text { Average Test } \\
\text { Performance (\%) }\end{array}$ & $\begin{array}{l}\text { Average Test Error } \\
(\%)\end{array}$ \\
\hline 1 & Backwards Passes 25\% (Lower Quartile) & 70.0 & 10.7 \\
2 & Short Passes (Maximum) & 70.0 & 9.4 \\
3 & Interceptions (Maximum) & 80.0 & 8.1 \\
4 & Shots on Target Inside the Box (Mean) & 80.0 & 6.8 \\
5 & Sideways Passes Unsuccessful (Mean) & 80.0 & 6.6 \\
6 & Sideways Passes Successful 75\% (Upper Quartile) & 90.0 & 5.5 \\
7 & Passes Successful Own Half (Mean) & 90.0 & 5.5 \\
8 & \% Passes Successful Opp Half (Minimum) & 80.0 & 6.3 \\
9 & \% Sideways Passes Successful (Median) & 90.0 & 6.4 \\
10 & Shots On Tgt Outside the Box (Mean) & 85.0 & 6.6 \\
\hline
\end{tabular}


Table 10. Results for Group $0 \mathrm{v}$ Group 2 Centre Back balanced data set comparison. The best average test performance $=100 \%$ and the best average test error $=1.0 \%$ (Using a combination of eighteen variables).

\begin{tabular}{|c|c|c|c|}
\hline Rank & Variable & Average Test Performance (\%) & Average Test Error $(\%)$ \\
\hline 1 & 0-6 Assists (Mean) & 80.0 & 8.1 \\
\hline 2 & Shots on Target Inside the Box (Mean) & 80.0 & 5.8 \\
\hline 3 & Penalty Area Entries (Minimum) & 90.0 & 4.4 \\
\hline 4 & International Caps & 90.0 & 3.7 \\
\hline 5 & Long Passes 25\% (Lower Quartile) & 90.0 & 3.2 \\
\hline 6 & Shots Outside the Box (Mean) & 90.0 & 2.9 \\
\hline 7 & U21 Caps & 100.0 & 2.4 \\
\hline 8 & Possession Gained 75\% (Upper Quartile) & 100.0 & 1.5 \\
\hline 9 & Avg Time in Possession (Median) & 100.0 & 1.5 \\
\hline 10 & Clearances (Maximum) & 100.0 & 1.2 \\
\hline 11 & Shots Outside the Box (Median) & 100.0 & 1.1 \\
\hline 12 & First Time Passes (Mean) & 100.0 & 1.3 \\
\hline 13 & Unsuccessful Passes (Minimum) & 100.0 & 1.4 \\
\hline 14 & Interceptions 75\% (Upper Quartile) & 100.0 & 1.3 \\
\hline 15 & Possession Gained (Minimum) & 100.0 & 1.3 \\
\hline 16 & Shots Inside the Box 25\% (Lower Quartile) & 100.0 & 1.1 \\
\hline 17 & Total Shots on Target (Mean) & 100.0 & 1.2 \\
\hline 18 & Tackled (Minimum) & 100.0 & 1.0 \\
\hline 19 & Final Third Entries (Mean) & 100.0 & 1.0 \\
\hline 20 & Medium Passes 25\% (Lower Quartile) & 100.0 & 1.3 \\
\hline
\end{tabular}


Table 11. Results for Group 0 v Group 1 Wide Midfield balanced data set comparison. The best average test performance $=79.4 \%$ and the best average test error $=8.2 \%$ (Using a combination of nine variables).

\begin{tabular}{llll}
\hline Rank & Variable & $\begin{array}{l}\text { Average Test Performance } \\
(\%)\end{array}$ & Average Test Error (\%) \\
\hline 1 & \% Unsuccessful Headers (Maximum) & 70.6 & 10.8 \\
2 & Forward Passes Successful 75\% (Upper Quartile) & 73.5 & 10.0 \\
3 & Possession Won 75\% (Upper Quartile) & 70.6 & 9.8 \\
4 & Shooting Accuracy 25\% (Lower Quartile) & 76.5 & 8.9 \\
5 & \% Unsuccessful Headers 75\% (Upper Quartile) & 79.4 & 8.5 \\
6 & \% Successful Headers (Median) & 76.5 & 8.4 \\
7 & Sideways Passes Successful 75\% (Upper Quartile) & 76.5 & 8.2 \\
8 & Fouls (Mean) & 76.5 & 8.1 \\
9 & Tackled (Maximum) & 79.4 & 8.2 \\
10 & Passes Attempted Opp Half (Mean) & 76.5 & 8.0 \\
\hline
\end{tabular}

Table 12. Results for Group $1 \mathrm{v}$ Group 2 Wide Midfield balanced data set comparison. The best average test performance $=77.8 \%$ and the best average test error $=7.4 \%$ (Using a combination of nine variables).

\begin{tabular}{llll}
\hline Rank & Variable & $\begin{array}{l}\text { Average Test Performance } \\
(\%)\end{array}$ & Average Test Error (\%) \\
\hline 1 & U21 International Caps & 66.7 & 10.3 \\
2 & Forwards Passes Unsuccessful (Median) & 77.8 & 9.3 \\
3 & \% Sideways Passes Unsuccessful (Median) & 77.8 & 9.1 \\
4 & Fouls (Mean) & 77.8 & 8.9 \\
5 & Possession Won (Maximum) & 77.8 & 8.6 \\
6 & \% Unsuccessful Headers (Maximum) & 77.8 & 8.5 \\
7 & Backwards Passes Unsuccessful (Maximum) & 77.8 & 8.7 \\
8 & Possession Lost (Maximum) & 77.8 & 7.9 \\
9 & Possession Won (Minimum) & 77.8 & 7.4 \\
10 & \% Unsuccessful Headers 25\% (Lower Quartile) & 77.8 & 7.6 \\
\hline
\end{tabular}


Table 13. Results for Group 0 v Group 2 Wide Midfield balanced data set comparison. The best average test performance $=100 \%$ and the best average test error $=3.4 \%$ (Using a combination of six variables).

\begin{tabular}{llll}
\hline Rank & Variable & Average Test Performance (\%) & $\begin{array}{l}\text { Average Test Error } \\
(\%)\end{array}$ \\
\hline 1 & Total Goals & 84.6 & 7.2 \\
2 & Passes Attempted Opp Half 75\% (Upper Quartile) & 84.6 & 6.3 \\
3 & Fouls in Defensive 3rd (Mean) & 84.6 & 6.1 \\
4 & Total Shots on Tgt (Excluding Blocked) & 92.3 & 4.5 \\
& (Maximum) & 3.3 \\
5 & \% Forwards Passes Successful (Mean) & 92.3 & 3.4 \\
7 & Forward Passes Successful (Median) & 100.0 & 3.7 \\
8 & Tackled 75\% (Upper Quartile) & 92.3 & 3.6 \\
9 & Backwards Passes Unsuccessful (Mean) & 92.3 & 3.5 \\
\hline
\end{tabular}

Table 14. Results for Group $0 \mathrm{v}$ Group 1 Centre Midfield balanced data set comparison. The best average test performance $=78.6 \%$ and the best average test error $=9.6 \%$ (Using a combination of nine variables).

\begin{tabular}{llll}
\hline Rank & Variable & $\begin{array}{l}\text { Average Test Performance } \\
(\%)\end{array}$ & $\begin{array}{l}\text { Average Test Error } \\
(\%)\end{array}$ \\
\hline 1 & Fouls & 57.1 & 11.5 \\
2 & First Time Passes (Maximum) & 64.3 & 10.9 \\
3 & Backwards Passes 75\% (Upper Quartile) & 64.3 & 10.6 \\
4 & Number of Touches (Median) & 64.3 & 10.6 \\
5 & Fouls (Maximum) & 64.3 & 10.5 \\
6 & Total Minutes & 71.4 & 9.9 \\
7 & \% Forward Passes Unsuccessful 25\% (Lower & 71.4 & 9.6 \\
& Quartile) & 71.4 & 9.6 \\
9 & Sideways Passes (Median) & 78.6 & 9.6 \\
10 & Passes Attempted Opp Half (Minimum) & 71.4 & 9.7 \\
\hline
\end{tabular}


Table 15. Results for Group 1 v Group 2 Centre Midfield balanced data set comparison. The best average test performance $=88.9 \%$ and the best average test error $=5.9 \%$ (Using a combination of five variables).

\begin{tabular}{llll}
\hline Rank & Variable & $\begin{array}{l}\text { Average Test Performance } \\
(\%)\end{array}$ & $\begin{array}{l}\text { Average Test Error } \\
(\%)\end{array}$ \\
\hline 1 & Successful Passes 25\% (Lower Quartile) & 66.7 & 10.2 \\
2 & Penalty Area Entries 25\% (Lower Quartile) & 66.7 & 9.6 \\
3 & Goals (Mean) & 77.8 & 8.4 \\
4 & Backwards Passes Unsuccessful (Mean) & 88.9 & 6.2 \\
5 & First Time Passes Successful (Maximum) & 88.9 & 5.9 \\
6 & Backwards Passes (Median) & 88.9 & 6.2 \\
7 & \% Sideways Passes Successful 25\% (Lower Quartile) & 88.9 & 6.4 \\
8 & Total Shots 25\% (Lower Quartile) & 88.9 & 6.4 \\
9 & Passes Own Half (Mean) & 88.9 & 6.9 \\
10 & Dribbles 75\% (Upper Quartile) & 83.3 & 7.2 \\
\hline
\end{tabular}

Table 16. Results for Group $0 \mathrm{v}$ Group 2 Centre Midfield balanced data set comparison. The best average test performance $=90.9 \%$ and the best average test error $=4.8 \%$ (Using a combination of ten variables).

\begin{tabular}{llll}
\hline Rank & Variable & $\begin{array}{l}\text { Average Test Performance } \\
(\%)\end{array}$ & $\begin{array}{l}\text { Average Test Error } \\
(\%)\end{array}$ \\
\hline 1 & No. Of Starts & 72.7 & 9.6 \\
2 & Shots On Tgt Outside the Box (Maximum) & 81.8 & 8.6 \\
3 & Possession Lost (Maximum) & 77.3 & 8.0 \\
4 & Forwards Passes (Mean) & 81.8 & 7.2 \\
5 & Possession Won (Median) & 81.8 & 6.0 \\
6 & Clearances 25\% (Lower Quartile) & 81.8 & 5.5 \\
7 & Total Shots on Target (Mean) & 90.9 & 5.2 \\
8 & Total Blocked Shots (Maximum) & 90.9 & 5.2 \\
9 & Forwards Passes (Median) & 90.9 & 4.9 \\
10 & \% Passes Successful Opp Half 75\% (Upper Quartile) & 90.9 & 4.8 \\
\hline
\end{tabular}


Table 17. Results for Group $0 \mathrm{v}$ Group 1 Attacker balanced data set comparison. The best average test performance $=80.0 \%$ and the best average test error $=8.7 \%$ (Using a combination of five variables).

\begin{tabular}{llll}
\hline Rank & Variable & Average Test Performance (\%) & Average Test Error (\%) \\
\hline 1 & International Caps & 73.3 & 10.4 \\
2 & Number of Touches 25\% (Lower Quartile) & 73.3 & 9.2 \\
3 & First Time Passes (Maximum) & 73.3 & 9.1 \\
4 & Blocks (Maximum) & 73.3 & 8.9 \\
5 & Final Third Entries (Mean) & 80.0 & 8.7 \\
6 & Passes Successful Own Half (Median) & 73.3 & 8.9 \\
7 & \% Successful Passes (Maximum) & 73.3 & 9.2 \\
8 & Tackled 25\% (Lower Quartile) & 73.3 & 9.0 \\
9 & \% Forwards Passes Successful (Minimum) & 73.3 & 9.1 \\
10 & \% Passes Successful Opp Half (Minimum) & 73.3 & 9.1 \\
\hline
\end{tabular}

Table 18. Results for Group $1 \mathrm{v}$ Group 2 Attacker balanced data set comparison. The best average test performance $=81.8 \%$ and the best average test error $=7.2 \%$ (Using a combination of six variables).

\begin{tabular}{llll}
\hline Rank & Variable & Average Test Performance (\%) & Average Test Error (\%) \\
\hline 1 & U21 International Caps & 63.6 & 11.0 \\
2 & International Caps & 72.7 & 9.9 \\
3 & Unsuccessful Passes (Maximum) & 72.7 & 9.6 \\
4 & Interceptions (Maximum) & 72.7 & 8.7 \\
5 & Possession Won (Median) & 81.8 & 7.2 \\
6 & \% Unsuccessful Passes 75\% (Upper Quartile) & 81.8 & 7.2 \\
7 & Final Third Entries 25\% (Lower Quartile) & 81.8 & 7.8 \\
8 & Tackles (Maximum) & 81.8 & 7.4 \\
9 & \% Unsuccessful Passes (Minimum) & 81.8 & 7.5 \\
10 & Penalty Area Entries (Minimum) & 81.8 & 7.3 \\
\hline
\end{tabular}



Table 19. Results for Group $0 \mathrm{v}$ Group 2 Attacker balanced data set comparison. The best average test performance $=92.3 \%$ and the best average test error $=2.6 \%$ (Using a combination of ten variables).

\begin{tabular}{llll}
\hline Rank & Variable & Average Test Performance (\%) & $\begin{array}{l}\text { Average Test Error } \\
(\%)\end{array}$ \\
\hline 1 & Total Goals & 76.9 & 7.6 \\
2 & Blocks 75\% (Upper Quartile) & 84.6 & 5.6 \\
3 & Short Passes (Minimum) & 92.3 & 5.0 \\
4 & Passes Own Half 25\% (Lower Quartile) & 92.3 & 4.4 \\
5 & \% Unsuccessful Headers (Maximum) & 92.3 & 4.0 \\
6 & Crosses (Mean) & 92.3 & 3.0 \\
7 & Avg Time in Possession 75\% (Upper Quartile) & 92.3 & 2.9 \\
8 & Interceptions (Median) & 92.3 & 3.0 \\
9 & Passes Successful Opp Half 75\% (Upper Quartile) & 92.3 & 3.0 \\
10 & Backwards Passes 25\% (Lower Quartile) & 92.3 & 2.6 \\
\hline
\end{tabular}

Table 20. Comparison of overall average test performance scores from position models as means and standard deviations.

\begin{tabular}{lll}
\hline Group Comparison & $\begin{array}{l}\text { Overall Average Test } \\
\text { Performance (\%) }\end{array}$ & Overall Average Test Error (\%) \\
\hline Group 0 v 1 Comparisons & $80.8 \pm 7.6$ & $8.1 \pm 2.3$ \\
Group 1 v 2 Comparisons & $82.7 \pm 6.6$ & $7.1 \pm 1.5$ \\
Group 0 v 2 Comparisons & $94.1 \pm 5.6$ & $3.7 \pm 2.1$ \\
\hline
\end{tabular}


Table 21. Group 0 v 2 Centre Back model variables represented as means and standard deviations for all player groupings.

\begin{tabular}{lll}
\hline Variables & Group 0 Centre Back & Group 2 Centre Back \\
\hline 0-6 Assists (Mean) & $0.1 \pm 0.1$ & $0.2 \pm 0.1$ \\
Shots on Target Inside the Box (Mean) & $0.2 \pm 0.2$ & $0.3 \pm 0.2$ \\
Penalty Area Entries (Minimum) & $0.2 \pm 0.4$ & $0.0 \pm 0.0$ \\
International Caps & $4.8 \pm 18.3$ & $9.2 \pm 14.6$ \\
Long Passes 25\% (Lower Quartile) & $4.3 \pm 2.2$ & $4.9 \pm 2.0$ \\
Shots Outside the Box (Mean) & $0.1 \pm 0.2$ & $0.1 \pm 0.1$ \\
U21 Caps & $0.3 \pm 0.9$ & $3.5 \pm 6.6$ \\
Possession Gained 75\% (Upper Quartile) & $34.2 \pm 5.5$ & $36.7 \pm 5.7$ \\
Avg Time in Possession (Median) & $2.4 \pm 2.2$ & $2.6 \pm 0.3$ \\
Clearances (Maximum) & $10.9 \pm 3.2$ & $11.4 \pm 3.2$ \\
Shots Outside the Box (Median) & $0.0 \pm 0.2$ & $0.0 \pm 0.0$ \\
First Time Passes (Mean) & $6.5 \pm 1.9$ & $7.0 \pm 1.2$ \\
Unsuccessful Passes (Minimum) & $1.4 \pm 1.8$ & $1.0 \pm 1.2$ \\
Interceptions 75\% (Upper Quartile) & $29.9 \pm 4.2$ & $31.1 \pm 5.3$ \\
Possession Gained (Minimum) & $21.1 \pm 4.9$ & $18.5 \pm 6.3$ \\
Shots Inside the Box 25\% (Lower Quartile) & $0.1 \pm 0.4$ & $0.0 \pm 0.1$ \\
Total Shots on Target (Mean) & $0.2 \pm 0.2$ & $0.3 \pm 0.2$ \\
Tackled (Minimum) & $0.2 \pm 0.7$ & $0.0 \pm 0.2$ \\
\hline
\end{tabular}


Table 22. Group 0 v 2 Wide Midfield model variables represented as means and standard deviations for all player groupings.

\begin{tabular}{lll}
\hline Variables & Group 0 Wide Midfield & Group 2 Wide Midfield \\
\hline Total Goals & $1.4 \pm 1.9$ & $5.5 \pm 3.8$ \\
Passes Attempted Opp Half 75\% (Upper Quartile) & $16.2 \pm 6.3$ & $21.4 \pm 5.8$ \\
Fouls in Defensive 3rd (Mean) & $0.2 \pm 0.2$ & $0.3 \pm 0.3$ \\
$\begin{array}{l}\text { Total Shots on Tgt (Excluding Blocked) } \\
\text { (Maximum) }\end{array}$ & $1.0 \pm 0.8$ & $2.6 \pm 1.1$ \\
\% Forwards Passes Successful (Mean) & & $55.2 \pm 9.7$ \\
Forward Passes Successful (Median) & $53.4 \pm 14.8$ & $6.1 \pm 2.2$ \\
Total Goals & $5.0 \pm 3.2$ & $5.5 \pm 3.8$ \\
Passes Attempted Opp Half 75\% (Upper Quartile) & $16.2 \pm 6.3$ & $21.4 \pm 5.8$ \\
Fouls in Defensive 3rd (Mean) & $0.2 \pm 0.2$ & $0.3 \pm 0.3$ \\
$\begin{array}{l}\text { Total Shots on Tgt (Excluding Blocked) } \\
\text { (Maximum) }\end{array}$ & $1.0 \pm 0.8$ & $2.6 \pm 1.1$ \\
\hline
\end{tabular}


Table 23. Group 0 v 1 Centre Back model variables represented as means and standard deviations for all player groupings.

\begin{tabular}{lll}
\hline Variables & Group 0 Centre Back & Group 1 Centre Back \\
\hline $\begin{array}{l}\text { \% Passes Successful Opp Half 75\% (Upper } \\
\text { Quartile) }\end{array}$ & $81.2 \pm 22.3$ & $92.4 \pm 13.5$ \\
Shooting Accuracy 75\% (Upper Quartile) & $23.5 \pm 35.6$ & $20.1 \pm 33.8$ \\
\% Successful Headers 75\% (Upper Quartile) & $51.0 \pm 8.7$ & $52.7 \pm 6.6$ \\
Balls Received 75\% (Upper Quartile) & $16.9 \pm 5.8$ & $20.6 \pm 8.9$ \\
Crosses (Median) & $0.1 \pm 0.3$ & $0.1 \pm 0.3$ \\
\% First Time Passes Successful 25\% (Lower & $59.3 \pm 13.0$ & $59.9 \pm 12.7$ \\
Quartile) & & \\
Total Shots on Target (Mean) & $0.2 \pm 0.2$ & $0.3 \pm 0.3$ \\
Passes Successful Opp Half (Minimum) & $0.2 \pm 0.5$ & $0.3 \pm 1.0$ \\
U21 Caps & $0.3 \pm 0.9$ & $1.3 \pm 3.2$ \\
Shooting Accuracy 25\% (Lower Quartile) & $0.0 \pm 0.0$ & $1.9 \pm 11.4$ \\
Medium Passes (Mean) & $7.9 \pm 2.9$ & $9.6 \pm 5.1$ \\
Forward Passes Successful (Minimum) & $1.5 \pm 1.3$ & $1.6 \pm 2.5$ \\
Total Shots on Tgt (Excluding Blocked) (Mean) & $0.1 \pm 0.1$ & $0.2 \pm 0.2$ \\
Goals (Mean) & $0.0 \pm 0.1$ & $0.1 \pm 0.1$ \\
\% Unsuccessful Headers 25\% (Lower Quartile) & $49.0 \pm 8.7$ & $47.2 \pm 6.7$ \\
Long Passes (Median) & $5.5 \pm 2.1$ & $6.3 \pm 2.5$ \\
\hline & & \\
\hline
\end{tabular}




\section{Supplementary Information}

The artificial neural network modelling involved a multi-layer perceptron architecture with a back-propagation algorithm. This algorithm used a sigmoidal transfer function and weights were updated by feedback from errors. The learning rate (the rate at which weights are updated as a proportion of the error) was set at 0.1 while the momentum (the proportion of the previous change in weights applied back to the current change in weights) was 0.5 and two hidden nodes (feature detectors) were used as part of the artificial neural network architecture in a single hidden layer. The maximum number of epochs (updates of the network) used was three hundred while the maximum number of epochs without improvement on the test was one hundred. This was used to prevent over fitting of the model. Results will be provided for the average test performance and the average test error. The average test performance indicates the percentage of test cases that are correctly predicted. The average test error is the root mean square error for the test data set, this indicates the difference between the values predicted by the model and the actual values of the test data set (Salkind, 2010). 